\title{
СОРТОВЫЕ ОСОБЕННОСТИ ВЕГЕТАТИВНОГО РАЗМНОЖЕНИЯ ГЛАДИОЛУСА ГИБРИДНОГО (GLADIOLUS HYBRIDA HORT.)
}

\author{
Хомутова Е. А. - кандидат с. -х. наук, \\ стариий научный сотрудник \\ лаборатории селекиии и \\ семеноводства иветочных культур \\ Левко Г. Д. - кандидат с. -х. наук, \\ заведуюший лабораторией селекиии и \\ семеноводства иветочных культур \\ ГНУ «Всероссийский НИИ \\ селекции и семеноводства \\ овошных культур» \\ россельхозакадемии \\ 143080, Россия \\ Московская область, п. ВНИИССОК \\ Тел.: +7 (495) 599-24-42 \\ E-mail: flowers@vniissok.ru
}

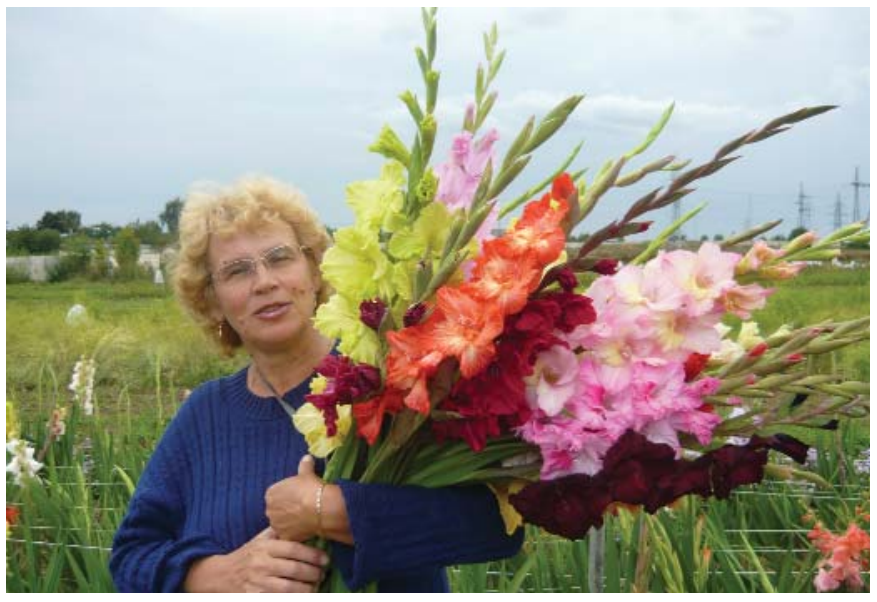

Проведен анализ коллекции сортов гладиолуса гибридного. Из 109 изученных 26 сортообразцов имели по 2-5 замещающих клубнелуковиц. Из них более 50\% сортов имели оранжево-лососевую и розово-малиновую окраску цветков, которая определяется антоциановыми пигментами. Причем, у сортов с белой, зеленой, желтой и розовой окраской цветка число замещающих клубнелуковиц не превымало 2 им. Самый низкий коэффициент вегемативного размножения был у сортов с голубой окраской. В эмой группе не было сортов, способных образовывать из одной материнской клубнелуковицы несколько новых.

гадиолус, или шпажник (Gladiolus L.), названный так по форме листьев, относится к большому семейству Ирисовые (Iridacea Juss). Относительно широкие приспособительные возможности и неприхотливость этого растения, а также способ выращивания, при котором обеспечивается перезимовка клубнелуковиц в защищенном от морозов помещении, позволяют культивировать его практически во всех климатических зонах: от Приполярья до субтропиков северного и южного полушарий (Лисянский Б.Г., Ладыгина Г.Г., 2001).

Селекцией и размножением гладиолуса гибридного занимаются во многих странах мира: в Канаде (Fleming, 1976), Голландии (Kramer, 1981), Италии (Talia, 1983), Франции (Bennerot, 1992), Румынии (Mariana, Constanta, Luminita, 2001), Польше (Mynett, Sanievski, Bijersvergen et al.,
1992), Бразилии (Tombolato, Castro, Matthes et al., 2002), Тайване (Chen, Chen W.H., Chen J.B., 1996), Индии (Arora, Misra, Bhattacharjee et al., 2002), Африке (Coetzee, Littlejohn, Venter et al., 2002), Kopee (Joung, Kim, Shin et al., 2003), Литве (Indrisiunaite, Dainauskaite, Forkmann et al., 2003) и других. Уже в 80-х годах XX века сортимент этой культуры насчитывал несколько тысяч культиваров, а к 2005 году - несколько десятков тысяч (Шашкова, 2007). В настоящее время наиболее крупным мировым центром селекции гладиолуса и промышленного производства посадочного материала и срезки цветов является США, причем в штате Флорида сосредоточено более 50\% этого производства (Manley, 1974). В Австралии, в штате Квинсленд, ежегодно выращивают до 1,5 млн. шт посадочного материала этой культуры (Мс Кау, Byth, Tommerup, 1981).
В Европе ведущей страной производителем луковиц гладиолуса является Голландия, где фирмы «Кониенбург и Марк» и «Сальмона» занимают лидирующее положение. В небольших объемах селекционная работа ведется в Германии фирмой «Пфитцер» (F. Stoop B.V., 2009).

В России селекцией гладиолуса начали заниматься в 20-30-х годах прошлого столетия. Работа с этой культурой ведется практически во всех агроклиматических зонах нашей страны, даже в таких достаточно суровых, как Урал и Сибирь.

Декоративные качества новых сортов отечественной селекции значительно улучшились и многие не уступают мировым стандартам, однако, ухудшились хозяйственно ценные признаки, особенно такие как «устойчивость к болезням» и «коэффициент вегетативного размножения». В современной селекции для скре- 
щиваний гладиолуса гибридного часто используют сорта американской и европейской селекции, которые имеют высокие декоративные показатели, но при этом в наших условиях зачастую плохо размножаются и часто поражаются болезнями. Поэтому для отечественных селекционеров первоочередной задачей является создание новых сортов с высокими декоративными и хозяйственно ценными признаками. цы хранили в помещении при температуре 3...8 0С и влажности воздуха $60-70 \%$ до следующего сезона.

Учет коэффициента вегетативного размножения проводили по «Методике первичного сортоизучения гладиолуса гибридного» по форме № 7 (Тамберг, 1972).

Все сорта по группам окрасок и сроку цветения были описаны согласно «Методическим рекомендациям ...» (2007). По срокам цветения сорта относились к очень ранним, жается в среднем числе клубнепочек, образовавшихся на одной клубнелуковице, или в среднем числе замещающих клубнелуковиц, образовавшихся на одной материнской клубнелуковице (в одном гнезде).

Клубнелуковица гладиолуса представляет собой метаморфизированный, сильно укороченный стебель, в котором откладывается большой запас питательных веществ, создающихся в течение лета за счет фотосинтеза зеленой массы листьев и ра-

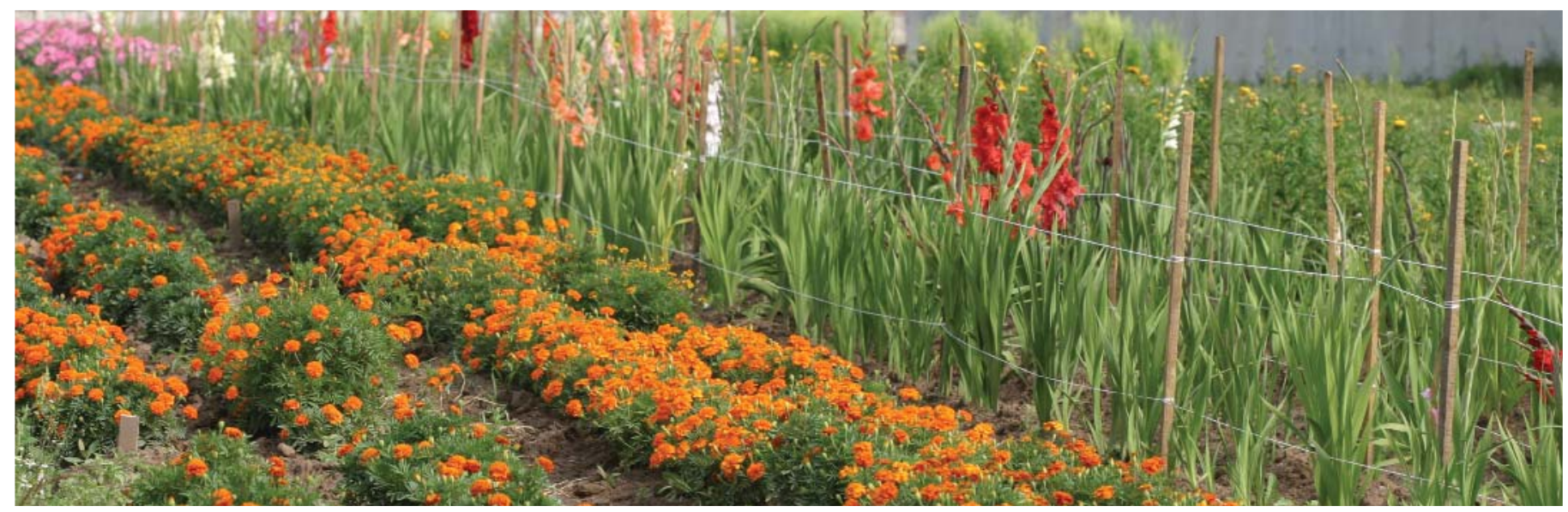

Материал и методы

Объектом исследований являлись 109 сортообразцов гладиолуса гибридного, высаженные 5 мая на площади 0,03 га по 15 клубнелуковиц в каждом сортообразце.

Посадку клубнелуковицами первого-второго разборов проводили на грядах, расстояние между грядами 70 см, между рядами и растениями в ряду - по 10-15 см. При посадке были внесены полные минеральные удобрения из расчета 20-25 г на погонный метр с заделкой в борозды на глубину 12-15 см.

В фазе начала образования третьего листа - 20 июня проводили первую подкормку, а 22 июля - в фазе начала цветения - вторую. В обоих случаях была внесена азофоска из расчета 25-30 г/м². Для снижения испарения и улучшения аэрации почвы участок пропалывали и одновременно рыхлили каждые 15 суток.

В конце августа - начале сентября все цветоносы удаляли, чтобы к моменту выкопки клубнелуковицы успели вызреть. Выкопанные клубнелуковицы просушивали 4 недели в сухом помещении с достаточным притоком воздуха при температуре $20 . .25$ ॰С.

После очистки и подсчета образ- ранним, среднеранним, средним и среднепоздним и были распределены по 11 группам окрасок цветков.

Результаты и их обсуждение

Одним из важных сортовых признаков для гладиолуса гибридного является «коэффициент вегетативного размножения», который выра-

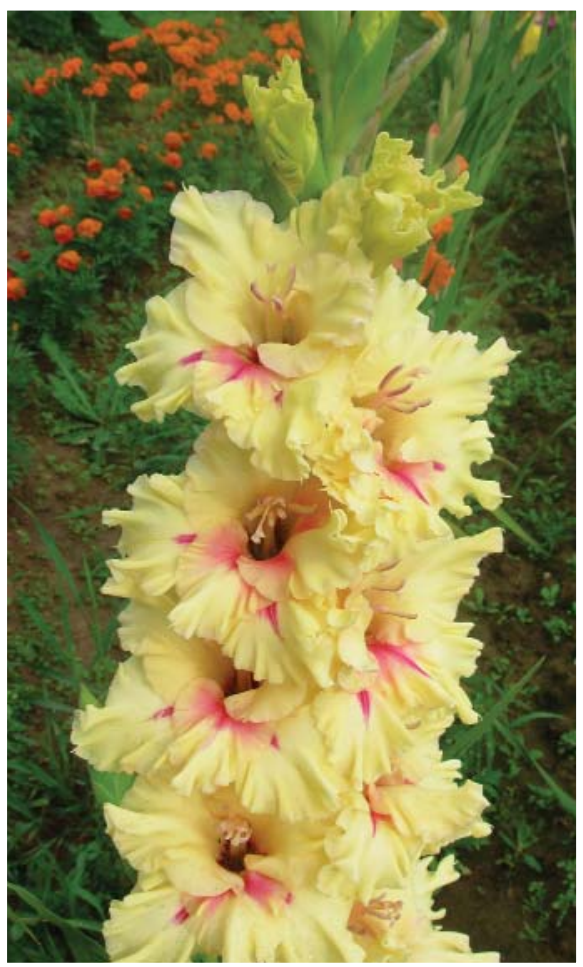

боты корневой и проводящей систем растения. Клубнелуковица образуется благодаря развитию нижних междоузлий и узлов оси. Старая материнская клубнелуковица, передав запасы питательных веществ и генетический код молодому растению, отмирает. Сформировавшаяся молодая дочерняя клубнелуковица по своим биологическим показателям является взрослым, достигшим половой зрелости растением (Громов, Ардабьевская, 2002).

У цветущей клубнелуковицы кроме центральной образуется еще несколько боковых почек с зачатками развивающегося цветоноса. У большинства сортов эти почки не развиваются. В неблагоприятные годы с резко колеблющейся температурой у значительного числа сортов развиваются 2-3 боковых соцветия, иногда их бывает до 4-5. В результате одна материнская клубнелуковица дает несколько молодых дочерних клубнелуковиц, которые и определяют коэффициент вегетативного размножения, т. е. соотношение посаженых клубнелуковиц к выкопанным.

Анализ коллекции сортов гладиолуса гибридного показал, что из 109 изученных 26 сортообразцов имели по 2-5 замещающих клубнелуковиц, 
из которых 14,6\% (16 сортов) имели по 2 клубнелуковицы и 9,2\% (10 сортов) - по 3-5 (табл. 1). Кроме того, из них более $50 \%$ сортов имели оранжево-лососевую и розово-малиновую окраску цветков, которая определяется антоциановыми пигментами. Причем, у сортов с белой, зеленой, желтой и розовой окраской цветка число замещающих клубнелуковиц не превышало 2 шт. Самый низкий коэффициент вегетативного размножения был у сортов с голубой окраской. В этой группе не было сортов, способных образовывать из одной материнской клубнелуковицы несколько новых.

\section{1. Сортоспецифичность признака "число замещающих клубнелуковиц" у гладиолуса гибридного(Gladiolus hybrida hort.), шт}

Все вновь образовавшиеся молодые дочерние клубнелуковицы в конце вегетационного периода по размеру соответствовали II и III разборам, которые на следующий год дают полноценные цветоносы.

Из литературных источников известно, что у поздних сортов, как правило, образуется одна замещающая клубнелуковица, в то время как у ранних сортов чаще в одном гнезде обра-

\begin{tabular}{|c|c|c|c|c|}
\hline \multirow{2}{*}{$\begin{array}{l}\text { Название сорта, } \\
\text { шифр окраски цветка }\end{array}$} & \multirow{2}{*}{$\begin{array}{l}\text { Срок } \\
\text { цветения }\end{array}$} & \multirow{2}{*}{$\begin{array}{l}\text { Окраска } \\
\text { цветка }\end{array}$} & \multicolumn{2}{|c|}{ Число замещающих клубнелуковиц, шт. } \\
\hline & & & две & от трех до пяти \\
\hline Белая Береза, 500 & $\mathrm{C}$ & белая & + & - \\
\hline Наш Сад, 402 & C & \multirow{2}{*}{ зеленая } & + & - \\
\hline Зеленый Какаду, 503 & $\mathrm{CP}$ & & + & - \\
\hline Нечаянная Радость, 512 & $\mathrm{CP}$ & \multirow{3}{*}{ желтая } & + & - \\
\hline Golden Years, 516 & C & & + & - \\
\hline Маргарита, 516 & $\mathrm{C}$ & & + & - \\
\hline Янтарная Балтика, 523 & $\mathrm{CP}$ & \multirow{4}{*}{ оранжевая } & + & - \\
\hline Майя Плисецкая, 420 & C & & - & + \\
\hline Королева Эстрады, 527 & C & & + & - \\
\hline Профессор Паролек, 427 & C & & + & - \\
\hline Русская Мадонна, 533/563 & C & \multirow{6}{*}{ лососевая } & - & + \\
\hline Джо Энн, 433 & C & & - & + \\
\hline Нижний Новгород, 535 & C & & + & - \\
\hline Ну, Громов, Погоди, 433 & C & & - & + \\
\hline Розовая Бегония, 534 & $\mathrm{CP}$ & & + & - \\
\hline Bell Tower, 534 & C & & + & - \\
\hline Pink Phantom, 442 & C & розовая & + & - \\
\hline Красная Стрела, 552 & $\mathrm{CP}$ & \multirow{2}{*}{ красная } & + & - \\
\hline Fareboll-2, 455 & $\mathrm{CP}$ & & - & + \\
\hline Дизайн, 567 & $\mathrm{CP}$ & \multirow{4}{*}{ малиновая } & - & + \\
\hline Grand Slam, 566 & $\mathrm{CP}$ & & - & + \\
\hline Легкое Дыхание, 562 & $\mathrm{CP}$ & & + & - \\
\hline Возрождение, 566 & C & & - & + \\
\hline Брызги Водопада, 472 & $\mathrm{CP}$ & \multirow{2}{*}{ сиреневая } & + & - \\
\hline Фронт Пейдж, 499 & $\mathrm{CP}$ & & - & + \\
\hline Конёк-Горбунок, 495 & $\mathrm{CP}$ & дымчатая & - & + \\
\hline
\end{tabular}


зуются 2-3 клубнелуковицы (Гладиолусы, 2004). Это подтвердилось и нашими исследованиями. Все отобранные сортообразцы, способные образовывать несколько дочерних клубнелуковиц, относились к группе средних и среднеранних сроков зацветания.

Однако при анализе сортообразцов, способных образовывать 3-5 замещающих клубнелуковиц, было отмечено, что все сорта с оранжевой и лососевой окраской цветка были среднего срока зацветания, а сорта красной, малиновой, сиреневой и дымчатой - среднераннего.

\section{Выводы}

Наибольшее число молодых дочерних клубнелуковиц образовывали следующие сорта: Майя Плисецкая - с оранжевой; Русская Мадонна, Джо Энн, Ну, Громов, Погоди, - с лососевой; Fareboll-2 - с красной; Дизайн, Grand Slam, Возрождение - с малиновой; Фронт Пейдж - с сиреневой и Конёк-Горбунок - с дымчатой окрасками цветка.

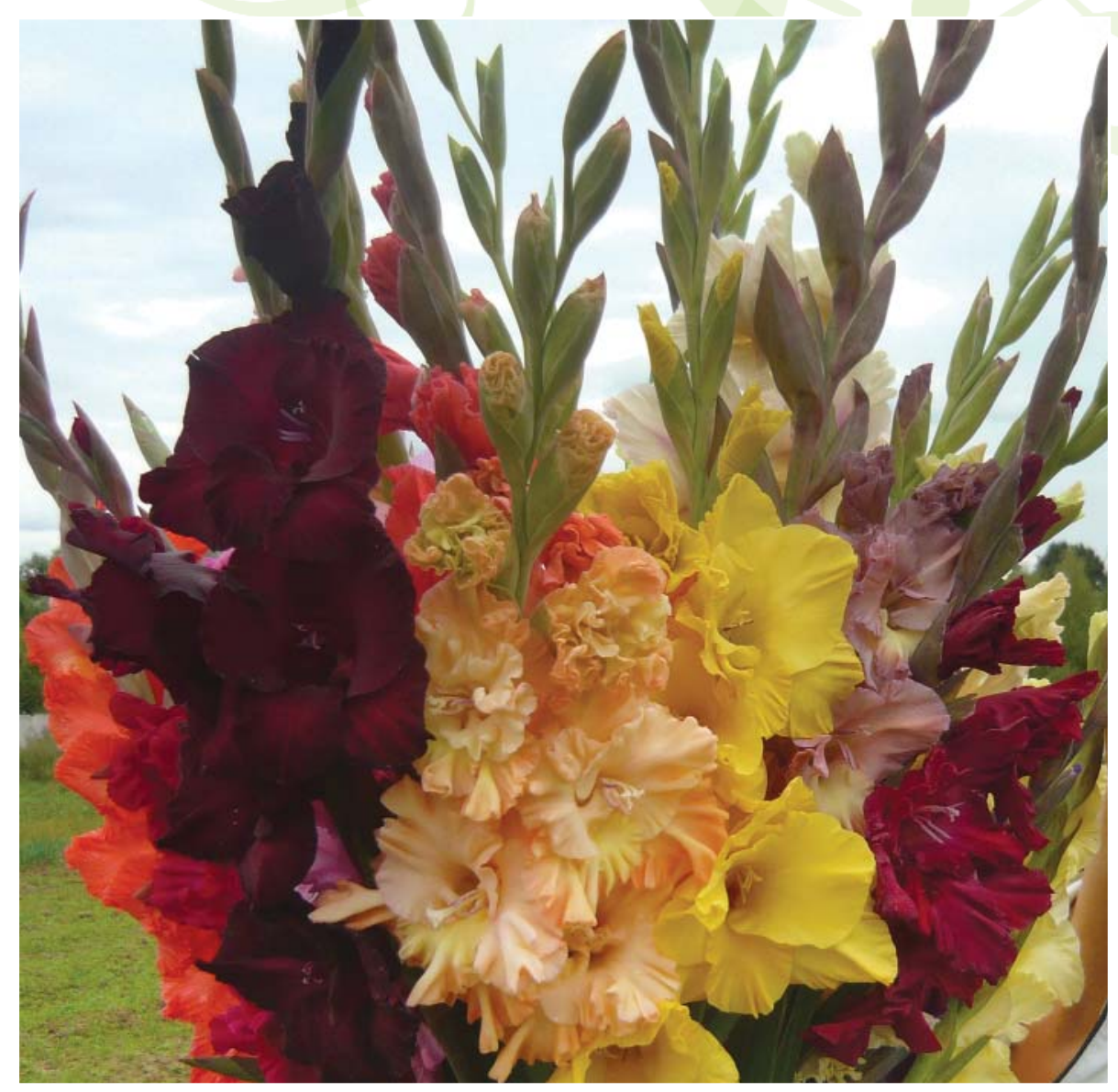

\section{Лиmерамура}

1. Громов А.Н., Ардабьевская Т.В. Гладиолусы. - М.: Олма-Пресс, Звездный мир, 2002. - 176 с.

2. Гладиолусы: выращивание и уход. - Минск.: Харвест, 2004. - 112 c.

3. Лисянский Б.Г., Ладыгина Г.Г. Гладиолусы. - М.: Астрель, 2001. - 144 с.

4. Методические рекомендации по сортоизучению гладиолуса гибридного (Gladiolus hybrida hort.). - М. - 2007. - 40 с. 5. Тамберг Т.Г. Методика первичного сортоизучения гладиолуса гибридного. - Л.: ВИР, 1972. - 19 с.

6. Тамберг Т.Г. Гладиолусы. - СПб.: Диамант, Золотой Век, Агропромиздат, 2000. - 189 с.

7. Шашкова Л.С. Мировые новинки в Москве //ЦветоводСтво. - 2007. - № 1. - С. 16

8. Arora J.S., Misra R.L., Bhattacharjee S.K., Singh K., Singh P. Gladiolus Techn. //Bull. AICRP on Floriculture. - 2002. - N. 14. $-100 \mathrm{pp}$.

9. Chen M.A., Chen W.H., Chen J.B. The development of horticulture in Taiwan Sugar Corporation //Taiwan Sugar. 1996. - V. 43, N. 2. - P. 32-34.

10. Coetzee J.H., Littlejohn G., Venter R., Lombard C. Benefit sharing from flowering bulb - is it still possible? //Acta Hort. 2002. - N. 570. - P. 21-27.

11. F.Stoop B.V. Specialist in Gladiolen. - 2009. - 98 s.

12. Fleming R. A. Gladiolus culture. - Ontario, 1976. - 11p.

13. Indrasiunaite G., Dainauskaite D., Forkmann G., Hauser B., Michaelis S. Investigations of gladioli (Gladiolus L.) in the Botanical Garden of Vilnius University //Acta Hort. - 2003. N. 612. - P. 181-186.
14. Joung H. Y., Kim H.D., Shin H.K., Choi S.Y., Kim J.Y., Lee J.M., Zhang D.L. Breeding of floricultural crops at NHRI, Korea. Asian plants with unique horticultural potential: genetic resources, culturalpractises and utilization //Acta Hort. 2003. - N. 620. - P. 231-238.

15. Kramer C. F. G. Gladiolen en tulpenteelt op het akkerbowbedrijf in het Zuidwestelijk kleigebied //Bedrijfsontwikkeling. - 1981. - Bd. 12, N. 5. - P. 504 - 506. 16. Manley T. Condition red - retooling for the eighties //North Amer. Gladiolus Council. Bull. - 1974. - N. 118. - P. $57-60$.

17. Mariana M., Constanta A., Luminita H. Achievements and prospects of flower breeding at R.I.V.F.G. Vidra. /Cercetari Stiintifice Horticultura, Universitatea de Stiinte Agricole si Medicina Veterinara a Banatului Timisoara, 2001. - P. 109120.

18. Mc Kay M. E., Byth D. E., Tommerup J. A. Environmental responses of gladioli in south-east Queensland //Sc. Hortic. 1981. - V.14, N.1. - P.77-92.

19. Mynett K., Saniewski M., Beijersvergen J. C. M., Bogatko W. Floriculture in Poland: research, education and production //Acta Hort. - 1992. - N. 325. - P. 29-34.

20. Talia M. La coltivazione di fieri e plante ornamental: in Italia // Inf. Ortoflorofruttic. - 1983. - V. 24, N. 11. P. 9 - 12.

21. Tombolato A. F. C., Castro J. L. de, Matthes L. A. F., deCastro J. L., Littlejohn G., Venter R., Lombardo C. Brazilian breeding program on Gladiolus spp. - history and first results //Acta Hort. - 2002. - N. 570. - P. 219-224. 